MISTRAL MISTRAL

Journal of Latin American Women's

Intellectual \& Cultural History

\title{
Infancias queer/cuir: Nuevas miradas sobre la infancia desde el sur
}

Alejandra Josiowicz, Universidade do Estado do Rio de Janeiro, Brasil

Cynthia Francica, Universidad Adolfo Ibáñez, Chile

María José Punte, Universidad de Buenos Aires / Universidad Católica Argentina

To cite this article: Alejandra Josiowicz, Cynthia Francica, y María José Punte. 2021. "Infancias queer/cuir: Nuevas miradas sobre la infancia desde el sur." Mistral: Journal of Latin American Women's Intellectual \& Cultural History 1 (2): 1-9, https://doi.org/10.21827/mistral.2.38025 


\title{
Infancias queer/cuir: Nuevas miradas sobre la infancia desde el sur
}

\author{
Alejandra Josiowicz, Universidade do Estado do Rio de Janeiro, Brasil \\ Cynthia Francica, Universidad Adolfo Ibáñez, Chile \\ María José Punte, Universidad de Buenos Aires / Universidad Católica Argentina
}

\begin{abstract}
¿Qué entendemos por infancia? La sola mención o evocación de esta etapa que todas/todos/todes compartimos por mera causalidad biológica, parece encapsular, como en una probeta, un concentrado de virtudes al que se puede recurrir una y otra vez ante el agotamiento o el desgaste que produce el transcurrir de la vida. La infancia, vista desde ahí, adquiere una densidad que es de cuño temporal. Abre una forma de temporalidad otra, ligada a lo que los griegos denominaban Aión, un tiempo que no es cronológico, sino que se concibe como del orden del acontecimiento (Kohan 2007). Es un tiempo que nos rescata de la eterna repetición de lo mismo, porque trae consigo siempre la novedad; pero que, a su vez, no se encuentra atado a la linealidad irreductible de la temporalidad cronológica. La infancia, por otra parte, tiene su historicidad, como se ve en los modos en los que se ha organizado la distribución espacial de los cuerpos, sobre todo a partir de los avances del sistema capitalista con su obsesión por la optimización de los recursos y el aplastamiento de las posibles rebeliones (Federici 2010). Esto tuvo como primer efecto que las narraciones dedicadas a esta etapa de la vida quedaran confinadas a los rincones menos prestigiosos de la cultura durante largo tiempo, como describe Philippe Ariès en Centuries of Childhood (1962), un texto que abre la puerta para empezar a pensar en torno a la pregunta inicial, es decir, la construcción socio-histórico-cultural de un imaginario en torno de lo infantil. El deseo de exactitud en la datación y en la nominación que Ariès ubica como una novedad del siglo XVI es uno de los factores que parece quedar en foco cuando la infancia entra en escena, desencadenando un esquema de proporciones que ha sido diseñado desde entonces a la medida de los sujetos adultos y en función de un concepto fuertemente institucionalizado de la vida familiar. La figura del infante no deja de ser de tipo relacional, dependiente de cómo cada entorno socio-histórico y cultural categoriza las fases de la vida. A su vez, el historiador francés hace notar que la infancia queda sometida a procesos arcaizantes y feminizantes que la apartan hacia los márgenes menos dinámicos de las sociedades.

$\mathrm{Y}$, sin embargo, las infancias son plurales y dinámicas. Los/las/les menores de edad no circulan como una abstracción nostálgica, ni como idealización estática de un estado perdido en un lugar ya inalcanzable, sino como cuerpos normativizados por un sistema biopolítico que pone particular énfasis en regular, medicalizar y controlar a una franja poblacional con el fin de garantizar la continuidad de la vida en términos de futuridad (Edelman 2004). Que exista una infancia del "hombre", nos dice Agamben universalizando el masculino, supone que sea posible la experiencia, porque la in-fancia es lo que constituye al lenguaje de una manera esencial. Agamben traduce infancia como la "experiencia en cuanto límite trascendental del lenguaje" (70), porque su preocupación es que el lenguaje se presente como totalidad y como verdad. Resulta por demás curioso que
\end{abstract}


se recurra a subjetividades a las que se les impiden los actos de habla, en el peor de los casos, o se los tolera como un ruido de fondo en sociedades más consentidoras, para referirse a aquello que debería ser el reaseguro de que el lenguaje subsista más allá de los meros juegos wittgenstinianos. Si los/las/les infantes son quienes vienen a asegurar que la experiencia siga existiendo para el "hombre”, ¿por qué les negamos la posibilidad del habla y la participación civil o nos regodeamos en un silencio al que se lee como epifánico?

En el vaivén que produce, ese mismo impulso hace que las infancias vayan a parar al cajón de lo abyecto. Eso, y no su exterioridad con respecto al lenguaje instituido (el logos), provoca que queden pululando por los suburbios de la racionalidad, de lo decente, y de la inefabilidad. La infancia es una construcción. Las infancias continúan su existencia como pueden, en los lugares que les dejamos, zonas liberadas que descartamos o minimizamos una vez hecha la repartición. Sin embargo, a lo menor se le ha adjudicado un cierto valor revolucionario cuando se aplica a una perspectiva estética o literaria. Dice Adriana Astutti en su libro Andares clancos: "Una literatura menor es aquella que se encuentra en situación de producir enunciados nuevos, y por lo tanto de valor incierto, que no pertenecen ni reflejan a un sujeto individual ni a una comunidad real sino que son el agenciamiento (el rapto, el encuentro) de un sujeto real con una comunidad virtual (también real sin ser actual)" (2001, 16; cursiva en el original). De ahí, tal vez, el éxito de las infancias en el terreno de las producciones artísticas, tanto en la literatura, como en el cine y en las artes plásticas. La "ética de lo menor" que para Astutti se encuentra en determinados modos de encarar la fabulación (por lo tanto, en ciertas formas de volverse escritor/a/e), se evidencia en un estilo caracterizado por la potencia de devenir, de movimiento, de acción.

El rapto, citado fugazmente por Astutti, es la figura a la que recurren René Schérer y Guy Hocquenghem para pensar a contrapelo de lo que llaman la "infancia moderna", a la que no aspiran a destronar. Su propuesta va más bien en dirección a mirar en sesgo, abrir una posibilidad queer para leer la cultura desde una comprensión más atenta a la idea relacional que ofrece la noción epistemológica de la constelación. Quitar al rapto del lugar de pasividad bajo el que solemos interpretarlo y dotarlo de agencia implica pensar desde una óptica situada en el deseo y sus motivos insondables. Así es como estos autores comienzan su libro afirmando que "El niño está hecho para ser raptado, de esto no cabe duda. Su pequeñez, su debilidad, su hermosura invitan a ello. Nadie lo duda, empezando por él mismo" (1979, 9; aquí las cursivas nos pertenecen). El arrebatamiento, cuya seducción está en el gesto violento, es un componente de una fantasía que tiene que ver, antes que nada, con la ruptura de esa situación de confinamiento y tiempo pautado al que la Modernidad ha destinado la existencia de las infancias (Foucault 2010). Sirve como alimento de un mundo de fantasías constitutivo de ese cordón umbilical que une el estadio adulto con un supuesto paraíso perdido. Para la subjetividad infante, dicha fantasía supone liberarse del "envolvente pensamiento parental, del lento camino de la pedagogía" (11), una verdadera tela de araña. El rapto, nos dicen Schérer y Hocquenghem, es la puerta abierta a lo desconocido, lo monstruoso, lo inhumano (16). Revela lo que el niño es en su "preciosa individualidad" (36), porque allí pierde su legibilidad en términos de mera función de signo en la trama del esquema familiar, en tanto que sujeto enrolado para la supervivencia del mundo adulto. Lo que resulta importante recalcar en el caso de Schérer y Hocquenghem es la construcción de una poética del niño en que la imagen sexual de los niños no se lee en un sentido nostálgico, del recuerdo o las memorias, ni tampoco 
moralizante, sino como un modo de hacer presente la relación entre el deseo y la palabra. Quiebra los límites o las barreras claras entre inocencia y perversidad, liberando una zona poética en donde lo fundamental no es el remordimiento por el pasado ni la angustia por el desarrollo sexual desviado, sino la emergencia de un tipo de sexualidad sin edad, sin jerarquía y transversal a las normas de los géneros. En una dirección similar, el psicoanalista Adam Phillips, dice en The Beast in the Nursery (1998) que los niños son hedonistas, sólo preocupados por la erótica del placer. Por lo tanto, representan un tipo de sexualidad totalmente disociada de la procreación, anti reproductiva. El niño es un esteta, dice Phillips, involucrado en un proyecto absurdo y permanente de sublimación a través de modos sutiles, de mediaciones, de detalles.

And, along came Kathryn: así es como llegamos al aporte crucial para una reflexión sobre la noción de infancia que es el que hace Kathryn Bond Stockton en su libro The Queer Child or Growing Sideways in the Twentieth Century (2009). En este derrotero por las figuras infantes que atraviesan cierto entramado de producciones culturales contemporáneas, imbricadas en los actuales imaginarios transnacionales que circulan gracias a lo audiovisual, se abren posibilidades originales para reorientar las maneras en que el pensamiento crítico puede encarar los abordajes que tienen a niñes y adolescentes como objeto. En primer lugar, porque pone el acento en la cuestión de los motivos que no solo son una fuente de inspiración textual, sino el núcleo en donde se concentran las ansiedades, temores y fantasías con respecto a las infancias desde su concepción hasta la entrada en el periodo adulto (desde el feto, como demuestra Penélope Deutscher [2019], hasta la salida de la adolescencia). La pregunta por el qué es lo que moviliza al infante, en particular cuando lo que se coloca en el foco son aquellas motivaciones que se supone le son ajenas, como pueden ser los motivos sexuales o criminales, es una guía fructífera para relativizar nociones cristalizadas tales como la de inocencia o inimputabilidad. Pero también para desbaratar los sistemas de certezas en torno a las acciones en las que los/las/les sujetos infantes se hacen cargo de sus existencias y se desvían de los caminos trazados por las instituciones familiares y escolares. Les niñes se vuelven monstruosos y nos colocan espejos en los que les adultes no deseamos vernos. Cuando se los ausculta bajo la lupa que nos ofrece Stockton, los motivos dejan de ser misteriosos para hablarnos de manera muy elocuente.

Otra idea nodal de su libro, y que resulta muy productiva para interpretaciones textuales, es la noción de crecimiento que propone esta autora, al que entiende no como un proceso que se da de manera lineal y siguiendo una progresión dictada por la cronología, sino como una constelación de movimientos laterales que rodean a la figura infante, otorgándole de ese modo una profundidad de campo y una polisemia inusitadas. Esta concepción del crecimiento, al que la autora define como "de costado" (growing sideways), permite pensar al tiempo en su dimensión de simultaneidad, como existiendo de varias maneras que se superponen sin colidir. En consonancia con esta concepción, el espacio también se abre en sus múltiples posibilidades y no queda sujetado por la mera fijación, sino que se despliega bajo la convivencia de diferentes volúmenes. Reniega, a su vez, de un modo unívoco de entender el proceso de crecer o de devenir adulto, que en inglés se denomina to grow up, es decir, hacia arriba, lo que refuerza una idea lineal e ineluctable, que sugiere rigidez, estabilidad y jerarquía. Resulta muy plástica la imagen alternativa que ofrece la autora, inspirada en la pintura cubista, que imagina a la figura infante desplegándose hacia los costados, de forma asincrónica, a través de múltiples conexiones, 
también comparada con el crecimiento de las neuronas en el cerebro, generando relaciones que le permiten desarrollar diversas facetas de la subjetividad. Nada más alejado de una instancia que congela a las subjetividades infantes en el terreno de lo inefable, del misterio o de una causalidad única. En lugar de asociar a las infancias con una temporalidad irrecuperable (algo tan indemostrable y literario como puede ser el mito del paraíso perdido) o con una espacialidad miniaturizada hasta una habitabilidad imposible, la mirada descubre los matices de los diálogos intergeneracionales, lo que permite comprender el funcionamiento de la agencia en los/las/les menores.

La postulación de Stockton se coloca en abierta polémica con el teórico Lee Edelman, que en su libro No Future: Queer Theory and the Death Drive (2004), había planteado que la imagen del niño sería el núcleo fundamental de construcción del discurso de la reproductividad, la familia y el orden social. Lo queer quedaría definido, para Edelman, como negatividad, por una política oposicional; como todo aquello que se opone al niño y al relato de la reproductividad teleológica normativa a nivel social. En relación con el despliegue de esa futuridad normativa, Lauren Berlant plantea, por su parte, que en el contexto norteamericano los imaginarios de inocencia, pureza y pasividad asociados a la/os niña/os resultan clave, ya que remiten a la centralidad de la figura del infante en la conformación de los modelos de ciudadanía contemporáneos (1997). En contraposición a la persistencia de ese mandato reproductivo en los imaginarios y prácticas de lo colectivo, para Edelman lo queer sería la pulsión de muerte, la negación de lo simbólico lacaniano, y tendría en el hombre soltero la figura anti-familiar por excelencia. En abierta polémica con Edelman, Stockton plantea su teoría de que la infancia debe pensarse a través de la idea del "fantasma del niño gay", fantasma sin el cual no sería posible entender la infancia ni tampoco la cultura queer. Según ella, es posible pensar a cada niño como queer y a cada queer como un niño. El análisis de Stockton, en consonancia con los feminismos contemporáneos, no considera a la infancia como una abstracción, sino que piensa a partir de los vectores sexogenéricos, de clase, de etnia y de especie. De ese modo es que circulan gracias a su lectura diversos modelos para pensar las infancias: el niñx fantasmal gay, el niñx freudiano agresivo, el niñx normativo, el niñx queerizado por el dinero o por el color, el intervalo animal. Raspar en la superficie de todx infante, como apunta en otro texto, supone encontrar lo queer: "Scratch a child, you will find a queer" $(2004,278)$. Está refutando, de esa manera, otro de los binarismos con los que el sistema patriarcal se ha encargado de organizar de modo jerárquico y estamental a las sociedades modernas, el de adulto/infante.

El foco de Edelman y Stockton en las intersecciones entre los discursos en torno a la niñez y a las sexualidades queer resulta crucial, ya que pone el acento en los modos en que las subjetividades femeninas, feminizadas y disidentes se construyen en estrecha correlación con lo infantil. Mientras que las mujeres han sido históricamente infantilizadas, tanto en el plano político, negándoseles el acceso a los derechos ciudadanos, como en la arena intelectual y en sus representaciones culturales, los sujetos queer/cuir suelen ser descriptos a partir de metáforas relacionadas con la niñez. Percibidos como individuos que "malgastan su tiempo en actividades improductivas, viven inmersos en mundos de fantasía, y dependen como parásitos del esfuerzo ajeno" (Chinn 2013), los sujetos disidentes son a menudo caracterizados como habitando un perpetuo desfase temporal. En la literatura de América Latina, las infancias son reclamadas, problematizadas y exploradas desde sus potencialidades y a partir de sus múltiples desvíos. En tanto plataforma desde donde 
ensayar otras formas de decir y de hacer, los universos infantiles a menudo se despliegan, más que en pos de reafirmar modelos hetero-patriarcales de crecimiento, identidad y deseo, justamente para intervenir los lineamientos normativos en torno a la subjetividad, la temporalidad y la escritura.

Las infancias nos hablan a través de la literatura, así como de las diversas formas en las que palabra y/o imagen articulan sus sentidos. Esto no quiere decir por fuerza que en las textualidades encontremos representaciones que fijan y cristalizan dichas configuraciones. Pero sí que nos abren puertas de entrada para repensar o vislumbrar esos movimientos insumisos de los que habla Kathryn B. Stockton, que se despliegan en coordenadas temporo-espaciales. En este sentido, las estéticas y afectos relacionados con lo infantil habilitan, en una serie de productos culturales recientes, quiebres formales a nivel escritural y visual, así como también un abordaje renovado de las prácticas creativas a partir de la dimensión espacial y temporal del juego. También se puede decir que las obras de arte van conformando un archivo de lo contemporáneo que funciona como una coagulación temporal. Tanto la literatura como las artes visuales, plásticas y performáticas, parecen estar hoy deslumbradas con esas figuras que suelen circular de manera oblicua en los resquicios que un mundo adultocéntrico deja libres. Y con el término "deslumbrar" no nos referimos solo a la posible fascinación que producen, sino también al hecho de que por momentos esas figuraciones nos obturan la visión, dando cuenta de que existen espacios que la mirada no logra percibir con total claridad.

Para este dossier, convocamos a colegas -investigadores y autores- que vienen trabajando y creando desde la teoría queer/cuir diversas producciones culturales contemporáneas, o de modo específico se ocupan de estudiar las formas en que las infancias nos interpelan a través del arte y la literatura. Abrimos con los ejemplos dedicados a la narrativa con dos aportes que se concentran en la literatura del Cono Sur. El primer texto, escrito en tándem por Laura A. Arnés y Silvana Abal, aborda la novela 98 segundos sin sombra (2014) de la escritora boliviana Giovanna Rivero Santa Cruz, una figura destacada de la "nueva narrativa" de su país. Renovadora tanto del realismo como del género fantástico, su obra hace confluir tradiciones literarias como el gótico, la ciencia ficción, la novela erótica y el Bildungsroman. Su escritura, como la de muchas autoras contemporáneas, se enfoca en la cuestión del cuerpo y su vulnerabilidad. Esta novela da voz a una adolescente, lo que produce varios corrimientos frente a la tradición tanto histórica como literaria, a la vez que problematiza las construcciones del sentido común y de las normas, junto con las matrices generizadas de la cultura. Arnés y Abal resaltan que el protagonismo de una chica apunta a poner en foco aquello que los cuerpos pueden hacer como biopotencia y que la cultura no logra disciplinar. Las "vidas jóvenes" aparecen allí en su condición de imposibilidad, resultante de una dislocación temporal que las convierte en subjetividades espectrales. De ahí el deseo de la protagonista de poseer al menos la propia sombra durante los noventa y ocho segundos mencionados en el título, instante de absoluto control de lo propio, sin divisiones ni refracciones.

El segundo texto, escrito por Lorena Amaro, parte de la noción de anomalía para pensar los modos en que se cuenta o se rememora la infancia, porque es a través de los dispositivos biopolíticos que se convierte a las infancias en monstruosas. No resulta exagerado pensar a estas vidas como construidas a partir de la noción de zoé, la vida "pura" despojada de lo humano, cuando se tienen en cuenta las numerosas situaciones de marginalización y violencia que padecen les infantes hoy (esclavitud, migración, tráfico de 
cuerpos y de órganos, criminalización y minorización por parte de las políticas públicas). Amaro analiza dos novelas de autoras uruguayas publicadas en el año 2020: Debimos ser felices de Rafaela Lahore y Mugre rosa de Fernanda Trías. En ambas, son esbozadas infancias signadas por la enfermedad y por lo monstruoso, a través de relatos genealógicos que adquieren sentido a partir de los lazos materno-filiales. Sus estéticas, no obstante, son muy diversas: así como Trías retorna a la distopía, género textual que viene a caso en tiempos en los que se evidencia la fragilidad de los cuerpos en el marco de la necropolítica liberal, Lahora se mantiene dentro de una estética cotidiana cercana a lo que se ha dado en llamar en el Cono Sur una "narrativa de los hijos". Las dos novelas tienen en común que en ellas aparecen niños y niñas afectados por la violencia intrafamiliar.

El artículo de María José Punte, por su parte, confronta tres novelas argentinas que recurren a diversas formas del humor para desestabilizar las representaciones en torno a las infancias y los modos de administrar sus vidas. Los textos elegidos con el propósito de echar una mirada sobre los actuales contextos en los que se insertan los menores de edad son Quedate conmigo (2017) de I. Acevedo, La maldición de Jacinta Pichimahuida (2007) de Lucía Puenzo y Osos (2010) de Diego Vecchio. Las tres dan cuenta de la grave crisis social y económica inherente a la fase presente del capitalismo, que no deja de perpetuarse mediante un sistema mercantilista expoliador cuyas principales víctimas son las mujeres, sujetos feminizados y los menores de edad. En las tres novelas, la infancia funciona como un sello indeleble impreso en sus estéticas, que recupera una "biblioteca infante" alimentada por el cine y por la televisión. A su vez, circulan por allí algunas de las figuras que Stockton propone como ejemplos de la "infancia queer": la díada que arman la niña y su perro; el infante agresivo y su contracara, el inocente; el niño fantasmal gay; el infante hecho queer por el dinero y por la clase. Una constante de estas producciones se sostiene en los diálogos y confrontaciones con los imaginarios del universo infantil, no solo con los objetos que les han sido adjudicados (los juguetes, determinadas vestimentas y espacios, hábitos alimenticios, música), sino también con lo que Punte define como la "biblioteca infante" y que incluye tanto el enorme corpus de la literatura infantil y juvenil, como el amplio espectro de lo audiovisual. Un ejemplo de esto, tal y como aparecía analizado en el texto anterior, es la mencionada novela Osos de Diego Vecchio.

Ludmila Barbero, por su parte, se concentra específicamente en la reescritura de los cuentos de hadas que lleva a cabo Alejandra Pizarnik en una serie de obras algo dispersas. Para su detallado análisis, Barbero se dedica a una serie de prosas breves que incluye a "Violario" (1971), "La verdad del bosque" (1971), "A tiempo y no" (1968), "Aproximaciones" (1956-1958), "La enamorada" (1956), así como sus Diarios. Allí desfilan de manera torcida los personajes de Caperucita Roja, Blancanieves, la Bella Durmiente, la sirenita, o Hansel y Gretel. Pizarnik retorna a esos espacios encantados para auscultar sus elementos más siniestros en donde se cruzan violencia y sexualidad, para echar una mirada entre fascinada y horrorizada de la infancia a través de sus zonas anómalas.

Los usos de los imaginarios de infancia se vuelven políticos a través del arte como muestra el texto de Nicolás Cuello. Su objeto de estudio son los trabajos performáticos y artísticos de los grupos de activismo, cuyos trabajos son inseparables de la protesta callejera, como se ve en las agrupaciones Mujeres Públicas (2003), Fugitivas del Desierto (2004) y Serigrafías Queer (2007). Estos colectivos vinculados con los movimientos feministas, lésbicos y sexodisidentes, ejercen un gesto de apropiación queer de los 
imaginarios infantes en consonancia con la ocupación del espacio público. Juegos populares y juguetes son resemantizados con el fin de elaborar una crítica a las economías hetero-reproductivas. De ese modo, lo codificado como "lindo" o "ingenuo", los afectos asociados con la ternura y la alegría, son retomados para visibilizar, interrumpir o desviar los guiones productivos de la sexopolítica moderna. Ante los límites impuestos por una política straight, Cuello reflexiona en torno a la potencial fuerza desestabilizadora que los lenguajes expresivos de la protesta sexual exploran mediante estas apropiaciones "torcidas" de lo infantil.

El campo de lo audiovisual explícito se encuentra representado a través del texto, también escrito a cuatro manos, de Catalina Donoso Pinto y Lorena Herrera Phillips, en su análisis del filme documental Los sueños del castillo (2018) del realizador chileno René Ballesteros. En él se retrata la vida de un grupo de niños recluidos en una institución estatal por haber cometido delitos. La espectralidad, un rasgo definitorio de lo cinematográfico, aparece acentuada en el hecho de que el texto se concentra en la narración de los sueños que los jóvenes reclusos hacen entre sí y al equipo realizador. No es anecdótico que esta institución se encuentre en territorio mapuche, con lo que se suma otra marginalidad a la del infante, junto con la del gitano y el delincuente. El encierro aquí es literal, ejemplo de la institucionalización que, en el mismo acto de apartar a los menores del espacio público, expropia a estos cuerpos de su categoría de hablantes. La narración de los sueños, esa vida onírica que atrae al documentalista, sirve como una estrategia para saltarse este sistema de restricciones, pero también para cuestionar una lógica a la que podemos considerar androcéntrica y que condensa en sí toda una serie de posicionamientos de clase, género, etnia, edad (es hombre, blanco, occidental, adulto).

Con el objetivo de sumar la palabra de les escritores, el dossier incluye textos de autores. Diego Vecchio escribió a pedido "Solo osos", en el que nos abre la antecocina de su novela Osos (2010). Allí nos recuerda que la actitud lúdica es inseparable de la escritura, que escribir un libro supone ponerse a jugar con -al menos- una palabra. Es lo que él hizo con la palabra OSO, a la que se dedicó a manosear, hacer girar, dar vuelta. Este jugueteo permitió desplegarla en "direcciones inesperadas" en una lectura que, al queerizarla, le abrió sus potencialidades. Bastó tocar una palabra con la lengua para que el espacio se fuera llenando literalmente de osos de peluche y generando una forma de comunidad ursina atravesada por la compulsión del coleccionista. De eso da cuenta esta crónica que viene acompañada de algunas elocuentes imágenes. Pero, de nuevo, la pregunta vuelve a ser: ¿qué es un niño? A la que Vecchio cruza con la de ¿qué es la literatura?

El poema escrito por Fernanda Laguna, por su parte, nos instala en el deseo de seguir siendo siempre niña/e/os. El miedo a crecer se proyecta insistente sobre el texto, así como la figura de la madre, a quien está dirigido. El yo poético emerge aquí bajo la figura de una adulta infantilizada que parece necesitar, más que contarle a la madre sus problemas y traumas, su mera presencia -el texto la nombra varias veces hasta sentirla cerca, hasta "invocarla". Si el psicoanálisis remite al espacio adultocéntrico de la confesión, de la exploración de los miedos, del auto-conocimiento y el crecimiento personal, la relación madre-hija, sugiere el poema, se organiza simultáneamente en torno a la cercanía y al secreto, a la imposibilidad de decir, a la mirada ocluida. El desfase temporal y vital que habita la voz poética, una voz feminizada y cuir, se espeja en la imagen de la obra Yo y la luz (1994), también de Fernanda Laguna, que incluimos aquí. Esta pieza repone la práctica 
del juego como plataforma creativa, indagando en la materialidad de la luz en tanto elemento central del lenguaje del arte.

El dossier también incluye la entrevista, "Cómo el Niño me puso del revés: Una entrevista con la teórica queer Kathryn Bond Stockton" ("How 'the Child' Turned Me Sideways": An Interview with Queer Theorist Kathryn Bond Stockton). Stockton reflexiona sobre su intervención fundacional en el campo de los estudios de la infancia y la teoría queer, específicamente desde la teoría literaria, con la intención de quebrar una mirada nacionalista y etnocéntrica y abrir una perspectiva hacia y desde el Sur, que tenga en cuenta tensionamientos geopolíticos y raciales al mismo tiempo, hacia un pensamiento que considere las colonizaciones y los orientalismos que rodean a la infancia. La entrevista inédita abre la posibilidad, para el público ibero-americano, de establecer y profundizar el diálogo teórico-crítico con esta autora fundamental para el campo.

En cuanto a este dossier de "Infancias queer/cuir en la literatura y las artes latinoamericanas" que proponemos a través de la revista Mistral en idioma español (con la excepción de la entrevista a Kathryn B. Stockton), lo entendemos como el gesto de dar vuelta la brújula. En este caso, no en el sentido "nacionalista" que le da a esta metáfora la escritora brasileño-argentina Paloma Vidal (2016), sino en términos de acercar a lectores y colegas a las producciones que están teniendo lugar en el sur del continente americano, cambiando por una vez la orientación de la mirada. Nuestras lecturas de teorías provenientes del norte han sido claramente productivas para ir armando un entramado crítico útil para cuestionar concepciones establecidas con respecto a las infancias. El cruce entre las elaboraciones teóricas provenientes de Francia a cargo de René Schérer y Guy Hocquenghem, con los conceptos provistos por Kathryn B. Stockton, constituyen un eje de diálogo tan usual como establecido; en gran medida, canónico. Abrimos el juego en dirección al sur, lo que obligará a torcer un poco la cabeza, con la ilusión de hacer entrar a otro participante en estos diálogos inter y transoceánicos. La teoría queer/cuir nos abre un filón tan valioso como efectivo para repensar la noción de infancia y para abonar las entradas críticas a la vasta producción cultural sudamericana que, en su empeño de interpretar la realidad, nunca se ha desentendido de la tarea de cambiarla.

\section{Bibliografía citada}

Agamben, Giorgio. 2007 [1978 y 2001]. Infancia e historia. Destrucción de la experiencia $y$ origen de la historia. Traducción de Silvio Mattoni. Buenos Aires: Adriana Hidalgo.

Ariès, Philippe. 1962. Centuries of Childhood. A Social History of Family Life. New York: Alfred A. Knopf.

Astutti, Adriana. 2001. Andares clancos. Rosario: Beatriz Viterbo. 
Berlant, Lauren. 1997. The Queen of America Goes to Washington City: Essays on Sex and Citizenship. Durham: Duke University Press.

Chinn, Sarah. 2013. "II was a Lesbian Child': Queer Thoughts about Childhood Studies". En The Children's Table: Childhood Studies and the Humanities, editado por Anna Mae Duane, 149-166. Athens: University of Georgia Press.

Deutscher, Penelope. 2019. Crítica de la razón reproductiva. Los futuros de Foucault. Traducción de Fernando Bogado. Buenos Aires: Eterna Cadencia.

Edelman, Lee. 2004. No Future. Queer Theory and the Death Drive. Durham and London: Duke University Press.

Federici, Silvia. 2010. Calibán y la Bruja. Mujeres, cuerpo y acumulación originaria. Traducción de Verónica Hendel y Leopoldo Sebastián Touza. Buenos Aires: Tinta Limón.

Foucault, Michel. 2010. Los anormales. Buenos Aires: FCE.

Kohan, Walter O. 2007. Infancia, política y pensamiento. Ensayos de filosofía y educación. Buenos Aires: Del Estante.

Phillips, Adam. 1998. The Beast in the Nursery: On Curiosity and Other Appetites. New York: Vintage Books.

Schérer, René y Guy Hocquenghem. 1979 [1976]. Co-ire. Álbum sistemático de la infancia. Barcelona: Anagrama.

Stockton, Kathryn B. 2004. "Growing Sideways, or Versions of the Queer Child: The Ghost, the Homosexual, the Freudian, the Innocent, and the Interval of the Animal". En Curiouser: On the Queerness of Children, editado por Steven Bruhm and Natasha Hurley, 277-311. Minneapolis/London: University of Minnesota Press.

- 2009. The Queer Child: Or Growing Sideways in the Twentieth Century. Durham and London: Duke University Press.

Vidal, Paloma. 2016. "Y el origen siempre se pierde." Zama 8 (8): 129-139. 